\title{
Hydrophobic Materials Based on Fluorocarbofunctional Spherosilicates
}

\author{
Hieronim Maciejewski • Joanna Karasiewicz • \\ Michal Dutkiewicz • Bogdan Marciniec
}

Received: 30 April 2014 / Accepted: 14 November 2014 / Published online: 12 December 2014

(C) The Author(s) 2014. This article is published with open access at Springerlink.com

\begin{abstract}
Consecutive hydrosilylation-based syntheses were performed of silsesquioxanes containing mixed groups $1 \mathrm{H}, 1 \mathrm{H}, 2 \mathrm{H}, 2 \mathrm{H}$-perfluorooctyl (PFD) or octafluoropentyloxypropyl (OFP) and trimethoxysilylethyl (TMS) in different stoichiometric ratios. The presence of TMS makes it possible to form covalent bonds with substrates due to the reactivity of this group. All obtained derivatives were applied to hydrophobization of glass plates and by comparison of water contact angles (WCA) on modified surfaces the effect of silsesquioxane structure as well as TMS and fluoroalkyl group contents on hydrophobic properties was determined. Moreover, an additional glass plates surface modification was performed in order to obtain superhydrophobic surfaces. Two silica types of different specific surface $\left(300\right.$ and $130 \mathrm{~m}^{2} / \mathrm{g}$ ) and particle size $(7$ and $16 \mathrm{~nm})$ parameters were used in this case for initial surface modification in order to increase its roughness. Irrespectively of particle size of applied silica, a dependence was found between the increase in water contact angle and the number of fluoroalkyl substituents in a molecule.
\end{abstract}

H. Maciejewski ( $\square) \cdot$ J. Karasiewicz

Faculty of Chemistry, Adam Mickiewicz University in Poznan, Umultowska 89b, 61-614 Poznan, Poland

e-mail: maciejm@amu.edu.pl

H. Maciejewski

Poznan Science and Technology Park, Adam Mickiewicz University Foundation, Rubiez 46, 61-612 Poznan, Poland

M. Dutkiewicz - B. Marciniec

Centre for Advanced Technologies, Adam

Mickiewicz University in Poznan, Grunwaldzka

6, 60-718 Poznan, Poland
Keywords Spherosilicate · Hydrosilylation · Fluorinated . Hydrophobization

\section{Introduction}

In the last decade a growth in the interest in hydrophobic materials, and particularly in superhydrophobic ones, has been observed due to their unique properties and great application potential that can be used in many branches of industry [1]. The production of materials of such a type was preceded by a thorough observation of the nature that surrounds us and the nature was a source of inspiration for making attempts at copying and imitating it $[1,2]$ Generally, a surface with water contact angle greater than $150^{\circ}$ can be considered as superhydrophobic and non-wetting. The wettability of a surface depends on two factors: (i) its chemical composition and (ii) its structure (roughness). It is well known that maximum water contact angle (WCA) on a perfectly smooth surface is $120^{\circ}$ [3], and micro/nano structure must be developed for achieving superhydrophobic properties. Such an effect can be created by producing a rough surface from a hydrophobic material (for which WCA $>90^{\circ}$ ) or by modifying a rough surface with a compound of low value of surface free energy [1, 2]. In the case of chemical modification the most efficient are fluorinecontaining compounds $[4,5]$. In particular, the best effect is obtained by applying fluoro derivatives of organosilicon compounds which combine unique properties of the both components $[6,7]$. As a natural extension of the most recent interests of modern science to the fields of nanotechnology and fluorine-containing materials, fluorinated silsesquioxanes have emerged as a new class of compounds for surface modifications [8-11]. Polyhedral oligomeric silsesquioxanes (POSS) of the empirical formula $\left(\mathrm{RSiO}_{1.5}\right)_{n}$ with 
different possible structural representations have recently become the subject of growing interest in many branches of chemistry [12-18]. It is known that cage structure silsesquioxanes due to their unique properties, e.g. the rigid nanoscale silicon-oxygen core with a diameter of about $1.5 \mathrm{~nm}$, are often regarded as the smallest silica particle that can also influence the surface roughness and tunable properties of functional groups attached to silicon atoms. Therefore the fluorofunctional silsesquioxanes are good precursors for the synthesis of highly hydrophobic materials. Synthesis and characterization of several fluorinated POSS derivatives (F-POSS) were described by Mabry et al. $[19,20]$ who used two different routes of synthesis. The first one was the corner capping of hepta(3,3,3-trifluoropropyl)tricycloheptasiloxane trisodium silanolate with different fluoroalkyltrichlorosilanes that gave products with high yields (73-83\%) [19]. Contacts angles measured for this compound ranged from 108 to $122^{\circ}$ for water and 69 to $80^{\circ}$ for hexadecane. The second way of synthesis of F-POSS was the base-catalyzed condensation of fluoroalkyltriethoxysilanes in ethanolic solutions [20]. These compounds were characterized by different WCA values depending on the length of fluoroalkyl chain. The derivative containing heptadecafluorodecyl groups appeared to be the most hydrophobic crystalline material having WCA of $154^{\circ}$. Another method of synthesis of F-POSS was described by $\mathrm{He}$ et al. who utilized the reactivity of the vinyl group in octakis(vinyl)octasilsesquioxane or octakis(vinyldimethylsiloxy)octasilsesquioxane in the reaction with perfluoroalkyl thiol in the presence of AIBN [21]. The obtained derivative was applied (in the amount of 5\%) to the modification of polymethyl methacrylate (PMMA) which resulted in a considerable increase in WCA from $71^{\circ}$ for non-modified PMMA to $124^{\circ}$ for modified one. Polymethacrylates were also modified in the ATRP process, where F-POSS was introduced as a macroinitiator [22]. A similar approach was proposed for the synthesis of a modified polycaprolactam by the reaction of caprolactone with different amounts of heptakis(3,3,3-trifluoropropyl)(3hydroxypropyl)octasilsesquioxane in the presence of tin catalyst [23]. The best result $\left(\mathrm{WCA}=108^{\circ}\right)$ was observed for the polymer containing $20 \mathrm{wt} \%$ of F-POSS compared to $\mathrm{WCA}=70^{\circ}$ for the polymer alone. Fluorinated POSS derivatives were also used for dip-coating surface modification of various materials such as fabrics [8], polycarbonates [24] and aluminum plates [25]. Fluorocarbofunctional groups, in spite of their specific properties, surface properties in particular, are not reactive from a chemical point of view. Therefore to enable their attachment to the surface, they are applied from suitable solutions, often with the addition of silica or silica sol produced in the sol-gel process $[8,24]$. On the other hand, an ideal approach to the problem would be the application of silsesquiox- anes with mixed functional groups, which contain both fluorocarbofunctional and organic (reactive) groups. Such a group can make it possible, by formation of covalent bonds, to create a stable combination between fluorosilicon compounds and a mineral or polymer surface. However, literature reports on the synthesis of derivatives of such a type are scarce. From among the few examples one can mention silsesquioxane that was applied to the modification of aluminum (as an anticorrosive coating) which, besides two fluoroalkyl and four isooctyl groups, contained two 3-(N-(3-triethoxysilylpropyl)ureido)propyl groups [25]. The synthesis of such a derivative is time-consuming and proceeds in several steps. It is based on hydrolytic condensation (in basic medium) of three organofunctional silanes, namely $1 \mathrm{H}, 1 \mathrm{H}, 2 \mathrm{H}, 2 \mathrm{H}$-perfluorooctyltriethoxysilane, 3aminopropyltrimethoxysilane and isooctyltrimethoxysilane taken in the ratio of 2:2:4. The second step consists of the reaction of amino groups in the formed silsesquioxane with 3-isocyanatopropyltriethoxysilane which resulted in the formation of an ureido derivative having trialkoxysilyl terminal groups $[25,26]$. Our contribution to this field was the synthesis of functionalized silsesquioxanes via consecutive hydrosilylation of two different olefins. One of them was fluoroalkyl allyl ether and the other - allyl glycidyl ether. By applying a very effective catalyst, such as rhodium siloxide complex, it was possible to obtain silsesquioxane derivatives (with any stoichiometry of functional groups) with very high yields in a one-pot process proceeding in very mild conditions [27, 28]. Moreover, the developed method is very attractive from the economic viewpoint because it is characterized both by simple technology and the use of considerably cheaper starting materials than those employed to date. The main reagents are octakis(hydridodimethylsiloxy)octasilsesquioxane (that is obtained in a simple and fast way based on the method described in the literature [29]) and fluoroalkyl allyl ether. The preparation of the latter reagent is based on the Williamson reaction by using fluorinated alcohols (that are considerably cheaper than commonly used fluoroalkyl iodides) and allyl chloride [30]. In the present study, based on the developed method of consecutive hydrosilylation of different olefins, syntheses were performed of subsequent silsesquioxanes containing, besides fluoroalkyl groups, also trimethoxysilylethyl groups that are susceptible to hydrolysis and condensation and due to this ability they can form covalent bonds with a substrate surface. This is why we have exploited this reactivity to modify the glass plates and to determine the effect of applied silsesquioxanes on hydrophobic properties of coatings formed with their participation. Moreover, our study was aimed at establishing a possibility of the formation of superhydrophobic coatings based on fluorofunctional silsesquioxanes. 


\section{Experimental}

All commercially available chemicals were used as received without any further purification. 1H,1H,2H-perfluoro-1decene was purchased from Aldrich. The rhodium siloxide complex $\left[\left\{\mathrm{Rh}\left(-\mathrm{OSiMe} \mathrm{S}_{3}(\mathrm{cod})\right\}_{2}\right]\right.$ was synthesized according to the original procedure described by Marciniec et al. $[31,32]$. 1,1,2,2,3,3,4,4-Octafluoropentyl allyl ether was synthesized by the Williamson reaction [33] and octakis (hydridodimethylsiloxy) octasilsesquioxane was prepared according to the procedure described by Caetano et al. [29]. Glass plates were purchased from Thermo Scientific. Silica Aerosil 130 and Aerosil 300 were purchased from Evonik.

${ }^{1} \mathrm{H} \quad \mathrm{NMR}(300 \mathrm{MHz}),{ }^{13} \mathrm{C}$ NMR $(75 \mathrm{MHz})$, and ${ }^{29} \mathrm{Si}$ NMR(59 MHz) spectra were recorded on a Varian XL 300 spectrometer at room temperature using $\mathrm{C}_{6} \mathrm{D}_{6}$ as a solvent. Water contact angle was measured using Kruss DSA 100E Drop Shape Analyzer equipped with software-controlled (DAS4 2.0): $\mathrm{x}, \mathrm{y}, \mathrm{z}$-axis table, quadruple dosing unit, zoom and focus adjustment, illumination, camera with 780580 px resolution. All presented data are arithmetic means of values measured for 5 drops.

2.1 General Procedure for Syntheses of Silsesquioxanes Containing Mixed Functional Groups

Silsesquioxanes containing mixed functional groups (16) were synthesized according to previously described methodology with slight modifications [28]. Octakis (hydridodimethylsiloxy)octasilsesquioxane and 1,1,2,2,3,3,4,4octafluoropentyl allyl ether or $1 \mathrm{H}, 1 \mathrm{H}, 2 \mathrm{H}$-perfluoro-1decene in an appropriate stoichiometric amount, together with $50 \mathrm{~mL}$ of toluene, were placed in a three-necked roundbottom flask equipped with a thermometer, condenser, and magnetic bar. Next $\left[\left\{\mathrm{Rh}\left(-\mathrm{OSiMe}_{3}\right)(\mathrm{cod})\right\}_{2}\right]$ complex $\left(2.5 \times 10^{-6} \mathrm{~mol} \mathrm{Rh} / \mathrm{mol} \mathrm{Si}-\mathrm{H}\right)$ was added at room temperature and the solution was heated to $110^{\circ} \mathrm{C}$ and maintained at this temperature for $1 \mathrm{~h}$. After that time, an appropriate amount of vinyltrimethoxysilane in $5 \%$ excess was added and the reaction was carried out for another $1 \mathrm{~h}$. Then the reaction mixture was cooled and the solvent and excess of olefin were evaporated under vacuum to give crude products which were subsequently dissolved in methanol and filtered to remove unreacted substrate. After evaporation of methanol, clean products (1-6) were obtained as viscous oils in the yields of $62 \%, 57 \%, 54 \%, 97 \%, 89 \%$ and $86 \%$, respectively. NMR analysis of the products confirmed their structures.

(Tetrakis(perfluorodecyldimethylsiloxy))tetrakis (2-trimethoxysilylethyldimethylsiloxy) octasilsesquioxane (1) ${ }^{1} \mathbf{H}$ NMR $\left(\mathrm{C}_{6} \mathrm{D}_{6}, 298 \mathrm{~K}, 300 \mathrm{MHz}\right) \delta(\mathrm{ppm})=0.17(24 \mathrm{H}$, $\left.\mathrm{Si}\left(\mathrm{CH}_{3}\right)_{2}\right) ; 0.78\left(8 \mathrm{H}, \mathrm{SiCH}_{2}\right) ; 1.28\left(16 \mathrm{H}, \mathrm{CH}_{2} \mathrm{Si}\right) ; 2.13$ $\left(8 \mathrm{H}, \quad \mathrm{CH}_{2}\right) ; 3.48\left(36 \mathrm{H}, \quad \mathrm{OCH}_{3}\right),{ }^{13} \mathbf{C} \quad \mathbf{N M R}\left(\mathrm{C}_{6} \mathrm{D}_{6}\right.$, $298 \mathrm{~K}, 75.5 \mathrm{MHz}) \delta(\mathrm{ppm})=-1.12\left(\mathrm{Si}\left(\mathrm{CH}_{3}\right)_{2}\right) ; 7.21$ $\left(\mathrm{SiCH}_{2}\right) ; 8.99 \quad\left(\mathrm{CH}_{2} \mathrm{Si}\right) 25.34 \quad\left(\mathrm{CH}_{2}\right) ; 50.34\left(\mathrm{OCH}_{3}\right)$; $111.85\left(\mathrm{CF}_{2}\right) ; 115.66\left(\mathrm{CF}_{3}\right) ; 119.48\left(\mathrm{CF}_{2}\right) ; 125.63\left(\mathrm{CF}_{2}\right)$; $128.00\left(\mathrm{CF}_{2}\right) .{ }^{29} \mathrm{Si}$ NMR $\left(\mathrm{C}_{6} \mathrm{D}_{6}, 298 \mathrm{~K}, 59.6 \mathrm{MHz}\right) \delta$ $(\mathrm{ppm})=15.52\left(\mathrm{Si}\left(\mathrm{CH}_{3}\right)_{2}\right) ;-107.56(\mathrm{SiOSi})$.

(Hexakis(perfluorodecyldimethylsiloxy)) bis(2-trimethoxysilylethyldimethylsiloxy) octasilsesquioxane (2) ${ }^{1} \mathbf{H}$ NMR $\left(\mathrm{C}_{6} \mathrm{D}_{6}, \quad 298 \mathrm{~K}, \quad 300 \mathrm{MHz}\right) \delta(\mathrm{ppm})=0.16(24 \mathrm{H}$, $\left.\mathrm{Si}\left(\mathrm{CH}_{3}\right)_{2}\right) ; 0.79\left(4 \mathrm{H}, \mathrm{SiCH}_{2}\right) ; 1.27\left(16 \mathrm{H}, \mathrm{CH}_{2} \mathrm{Si}\right) ; 2.11$ $\left(12 \mathrm{H}, \quad \mathrm{CH}_{2}\right) ; 3.55 \quad\left(18 \mathrm{H}, \mathrm{OCH}_{3}\right) .{ }^{13} \mathbf{C} \quad \mathbf{N M R} \quad\left(\mathrm{C}_{6} \mathrm{D}_{6}\right.$, $298 \mathrm{~K}, 75.5 \mathrm{MHz}) \delta(\mathrm{ppm})=-1.18\left(\mathrm{Si}\left(\mathrm{CH}_{3}\right)_{2}\right) ; 7.20$ $\left(\mathrm{SiCH}_{2}\right) ; 9.29\left(\mathrm{CH}_{2} \mathrm{Si}\right) 25.34\left(\mathrm{CH}_{2}\right) ; 50.91 \quad\left(\mathrm{OCH}_{3}\right)$; $111.52\left(\mathrm{CF}_{2}\right) ; 116.22\left(\mathrm{CF}_{3}\right) ; 119.42\left(\mathrm{CF}_{2}\right) ; 121.96\left(\mathrm{CF}_{2}\right)$; $128.24\left(\mathrm{CF}_{2}\right) .{ }^{29} \mathrm{Si}$ NMR $\left(\mathrm{C}_{6} \mathrm{D}_{6}, 298 \mathrm{~K}, 59.6 \mathrm{MHz}\right) \delta$ $(\mathrm{ppm})=16.00\left(\mathrm{Si}\left(\mathrm{CH}_{3}\right)_{2}\right) ;-107.73(\mathrm{SiOSi})$.

(Heptakis(perfluorodecyldimethylsiloxy))(2-trimethoxysilylethyldimethylsiloxy) octasilsesquioxane (3) ${ }^{1} \mathbf{H}$ NMR $\left(\mathrm{C}_{6} \mathrm{D}_{6}, 298 \mathrm{~K}, 300 \mathrm{MHz}\right) \delta(\mathrm{ppm})=0.14\left(24 \mathrm{H}, \mathrm{Si}\left(\mathrm{CH}_{3}\right)_{2}\right)$; $0.82\left(2 \mathrm{H}, \mathrm{SiCH}_{2}\right) ; 1.31\left(16 \mathrm{H}, \mathrm{CH}_{2} \mathrm{Si}\right) ; 2.14\left(14 \mathrm{H}, \mathrm{CH}_{2}\right)$; $3.49\left(9 \mathrm{H}, \mathrm{OCH}_{3}\right),{ }^{13} \mathbf{C}$ NMR $\left(\mathrm{C}_{6} \mathrm{D}_{6}, 298 \mathrm{~K}, 75.5 \mathrm{MHz}\right) \delta$ $(\mathrm{ppm})=-1.20\left(\mathrm{Si}\left(\mathrm{CH}_{3}\right)_{2}\right) ; 7.46\left(\mathrm{SiCH}_{2}\right) ; 8.98\left(\mathrm{CH}_{2} \mathrm{Si}\right)$ $25.29\left(\mathrm{CH}_{2}\right) ; 50.32\left(\mathrm{OCH}_{3}\right) ; 108,78\left(\mathrm{CF}_{2}\right) ; 111.52\left(\mathrm{CF}_{2}\right)$; $116.51\left(\mathrm{CF}_{3}\right) ; 119.73\left(\mathrm{CF}_{2}\right) ; 128.00\left(\mathrm{CF}_{2}\right) .{ }^{29} \mathrm{Si} \mathbf{N M R}$ $\left(\mathrm{C}_{6} \mathrm{D}_{6}, 298 \mathrm{~K}, 59.6 \mathrm{MHz}\right) \delta(\mathrm{ppm})=15.34\left(\mathrm{Si}\left(\mathrm{CH}_{3}\right)_{2}\right)$; -107.16 (SiOSi).

(Tetrakis(1,1,2,2,3,3,4,4-octafluoropentyloxypropyldimethylsiloxy))tetrakis(2-trimethoxysilylethyldimethylsiloxy)octasilsesquioxane (4) ${ }^{1} \mathbf{H}$ NMR $\left(\mathrm{C}_{6} \mathrm{D}_{6}, 298 \mathrm{~K}, 300 \mathrm{MHz}\right)$ $\delta(\mathrm{ppm})=0.12\left(24 \mathrm{H}, \mathrm{Si}\left(\mathrm{CH}_{3}\right)_{2}\right) ; 0.51\left(24 \mathrm{H}, \mathrm{SiCH}_{2}\right) ; 1.51$ $\left(8 \mathrm{H}, \mathrm{CH}_{2}\right) ; 3.21\left(16 \mathrm{H}, \mathrm{OCH}_{2}\right) ; 3.43\left(36 \mathrm{H}, \mathrm{OCH}_{3}\right) ; 5.54$ $\left(4 \mathrm{H}, \mathrm{CF}_{2} \mathrm{H}\right) .{ }^{13} \mathbf{C}$ NMR $\left(\mathrm{C}_{6} \mathrm{D}_{6}, 298 \mathrm{~K}, 75.5 \mathrm{MHz}\right) \delta(\mathrm{ppm})$ $=-0.58\left(\mathrm{Si}\left(\mathrm{CH}_{3}\right)_{2}\right) ; 13.59\left(\mathrm{SiCH}_{2}\right) ; 23.29\left(\mathrm{CH}_{2}\right) ; 50.28$ $\left(\mathrm{OCH}_{3}\right) ; 67.58\left(\mathrm{OCH}_{2}\right) ; 75.45\left(\mathrm{OCH}_{2}\right) ; 104.84\left(\mathrm{CF}_{2}\right)$; $108.20\left(\mathrm{CF}_{2}\right) ; 111.55\left(\mathrm{CF}_{2} \mathrm{H}\right) ; 116.03\left(\mathrm{CF}_{2}\right) .{ }^{29} \mathrm{Si} \mathrm{NMR}$ $\left(\mathrm{C}_{6} \mathrm{D}_{6}, 298 \mathrm{~K}, 59.6 \mathrm{MHz}\right) \delta(\mathrm{ppm})=15.19\left(\mathrm{Si}\left(\mathrm{CH}_{3}\right)_{2}\right)$; -107.06 (SiOSi).

(Hexakis(1,1,2,2,3,3,4,4-octafluoropentyloxypropyldimethylsiloxy))bis(2-trimethoxysilylethyldimethylsiloxy)octasilsesquioxane (5) ${ }^{1} \mathbf{H}$ NMR $\left(\mathrm{C}_{6} \mathrm{D}_{6}, 298 \mathrm{~K}, 300 \mathrm{MHz}\right) \delta$ $(\mathrm{ppm})=0.16\left(24 \mathrm{H}, \mathrm{Si}\left(\mathrm{CH}_{3}\right)_{2}\right) ; 0.54\left(20 \mathrm{H}, \mathrm{SiCH}_{2}\right) ; 1.55$ $\left(12 \mathrm{H}, \mathrm{CH}_{2}\right) ; 3.22\left(24 \mathrm{H}, \mathrm{OCH}_{2}\right) ; 3.48\left(18 \mathrm{H}, \mathrm{OCH}_{3}\right) ; 5.46$ $\left(6 \mathrm{H}, \mathrm{CF}_{2} \mathrm{H}\right) .{ }^{13} \mathbf{C}$ NMR $\left(\mathrm{C}_{6} \mathrm{D}_{6}, 298 \mathrm{~K}, 75.5 \mathrm{MHz}\right) \delta(\mathrm{ppm})$ $=-0.54\left(\mathrm{Si}\left(\mathrm{CH}_{3}\right)_{2}\right) ; 13.60\left(\mathrm{SiCH}_{2}\right) ; 23.29\left(\mathrm{CH}_{2}\right) ; 50.32$ $\left(\mathrm{OCH}_{3}\right) ; 67.59\left(\mathrm{OCH}_{2}\right) ; 75.48\left(\mathrm{OCH}_{2}\right) ; 104.83\left(\mathrm{CF}_{2}\right)$; $108.18\left(\mathrm{CF}_{2}\right) ; 111.54\left(\mathrm{CF}_{2} \mathrm{H}\right) ; 116.06\left(\mathrm{CF}_{2}\right) .{ }^{29} \mathrm{Si} \mathbf{~ N M R}$ $\left(\mathrm{C}_{6} \mathrm{D}_{6}, 298 \mathrm{~K}, 59.6 \mathrm{MHz}\right) \delta(\mathrm{ppm})=15.33\left(\mathrm{Si}\left(\mathrm{CH}_{3}\right)_{2}\right)$; -107.03 (SiOSi). 
(Heptakis(1,1,2,2,3,3,4,4-octafluoropentyloxypropyldimethylsiloxy))(2-trimethoxysilylethyldimethylsiloxy)octasilsesquioxane (6) ${ }^{1} \mathbf{H} \mathbf{N M R}\left(\mathrm{C}_{6} \mathrm{D}_{6}, 298 \mathrm{~K}, 300 \mathrm{MHz}\right) \delta$ $(\mathrm{ppm})=0.16\left(24 \mathrm{H}, \mathrm{Si}\left(\mathrm{CH}_{3}\right)_{2}\right) ; 0.53\left(18 \mathrm{H}, \mathrm{SiCH}_{2}\right) ; 1.55$ $\left(14 \mathrm{H}, \mathrm{CH}_{2}\right) ; 3.23\left(28 \mathrm{H}, \mathrm{OCH}_{2}\right) ; 3.48\left(9 \mathrm{H}, \mathrm{OCH}_{3}\right) ; 5.48$ $\left(7 \mathrm{H}, \mathrm{CF}_{2} \mathrm{H}\right) .{ }^{13} \mathbf{C} \mathbf{N M R}\left(\mathrm{C}_{6} \mathrm{D}_{6}, 298 \mathrm{~K}, 75.5 \mathrm{MHz}\right) \delta(\mathrm{ppm})$ $=-0.55\left(\mathrm{Si}\left(\mathrm{CH}_{3}\right)_{2}\right) ; 13.60\left(\mathrm{SiCH}_{2}\right) ; 23.30\left(\mathrm{CH}_{2}\right) ; 50.46$ $\left(\mathrm{OCH}_{3}\right) ; 67.59\left(\mathrm{OCH}_{2}\right) ; 75.48\left(\mathrm{OCH}_{2}\right) ; 105.66\left(\mathrm{CF}_{2}\right)$; $108.48\left(\mathrm{CF}_{2}\right) ; 111.26\left(\mathrm{CF}_{2} \mathrm{H}\right) ; 115.76\left(\mathrm{CF}_{2}\right) .{ }^{29} \mathbf{S i} \mathbf{N M R}$ $\left(\mathrm{C}_{6} \mathrm{D}_{6}, 298 \mathrm{~K}, 59.6 \mathrm{MHz}\right) \delta(\mathrm{ppm})=15.33\left(\mathrm{Si}\left(\mathrm{CH}_{3}\right)_{2}\right)$; -107.03 (SiOSi).

\subsection{Cleaning Procedure}

Glass plates immersed in a detergent solution were placed on an ultrasonic bath for 15 minutes, then rinsed with demineralized water, immersed in acetone and sonicated for another 15 minutes. At the end, they were rinsed with demineralized water and dried in air at room temperature.

\subsection{Dip-coating Procedure}

Cleaned glass plates were coated with fluorofunctional compounds (1-6) by immersing in $5 \mathrm{wt}$. \% toluene solutions of the latter. Each glass plate was immersed for 5 minutes in a suitable POSS solution and allowed to dry for 3 minutes in air. This operation was repeated 3 times for all plates followed by baking the samples for $1 \mathrm{~h}$ at $120^{\circ} \mathrm{C}$ in air. One series of samples was also prepared by performing an additional sonication during modification.

\subsection{Preparation of Silica Solution and its Application on Glass Plates}

A mixture was prepared of $10 \mathrm{~g}$ tetraethoxysilane (TEOS), $40 \mathrm{~g}$ ethanol, $30 \mathrm{~g}$ water and $30 \mathrm{~g}$ aqueous ammonia and vigorously stirred for 3 hours at room temperature. A suitable amount of such a prepared sol was mixed with Aerosil 130 silica (particle size of $16 \mathrm{~nm}$ ) or Aerosil 300 silica (particle size of $7 \mathrm{~nm}$ ) at such a ratio to obtain $5 \mathrm{wt}$. $\%$ sol and $1.2 \mathrm{wt} . \%$ silica, followed by dissolving in ethanol. The mixture was vigorously stirred for 30 minutes at room temperature and then glass plates were immersed in it for 15 minutes. To apply the layer evenly on the plates, the operation was carried out under sonication. This was followed by drying of plates for $1 \mathrm{~h}$ at $120^{\circ} \mathrm{C}$. In the next step, glass plates were modified with a solution containing a suitable silsesquioxane with mixed functional groups, analogously to in the case of the dip-coating procedure.

\section{Results and Discussion}

The synthesis of fluorofunctional silsesquioxanes containing additionally trimethoxysilyl groups was based on the reaction of consecutive hydrosilylation of 1,1,2,2,3,3,4,4octafluoropentyl allyl ether or $1 \mathrm{H}, 1 \mathrm{H}, 2 \mathrm{H}$-perfluoro-1decene and then vinyltrimethoxysilane with the use of octakis(hydridodimethylsiloxy)octasilsesquioxane. The procedure was analogous to that described by us earlier for the synthesis of silsesquioxanes containing fluoroalkyl and glycidyl groups [28]. By a suitable choice of stoichiometric ratios of olefins, silsesquioxane derivatives were obtained of different, but strictly definite amount of fluoroalkyl and trimethoxysilyl groups. Six new derivatives of general formula given in Fig. 1 were obtained, isolated and spectroscopically characterized.

The aforementioned derivatives contain perfluorodecyl (PFD) and trimethoxysilylethyl (TMS) groups at ratios of 4:4 (1), 6:2 (2) and 7:1 (3), respectively, or octafluoropentyloxypropyl (OFP) and trimethoxysilylethyl (TMS) groups in analogous ratios of 4:4 (4), 6:2 (5) and 7:1 (6). All the derivatives were obtained with good yields, however, yields of derivatives containing OFP groups were considerably higher. Furthermore, the olefin used to prepare them, i.e. octafluoropentyl allyl ether is much cheaper compared to $1 \mathrm{H}, 1 \mathrm{H}, 2 \mathrm{H}$-perfluoro-1-decene. However, OFP in contradistinction to PFD, contains an oxygen atom and this fact can cause a deterioration of hydrophobizing properties. To establish the effect of the kind of fluoroalkyl group on hydrophobic properties, the modification of glass plates was
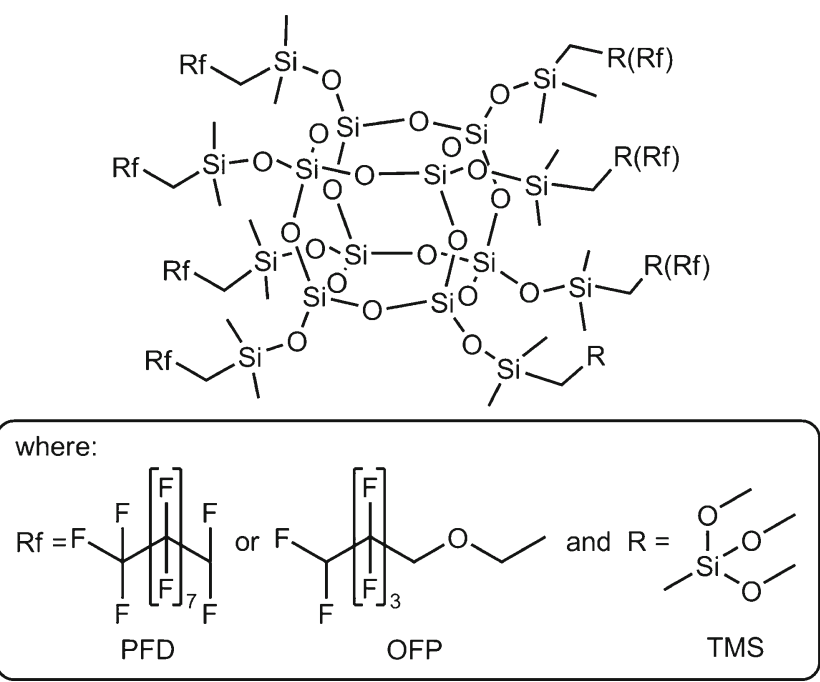

Fig. 1 General formula of synthesized fluorofunctional spherosilicates 
performed with the use of all silsesquioxanes synthesized. Two series of samples modified with the discussed derivatives were prepared. The standard procedure of immersion (dip-coating) was applied in the case of the first series of samples, whereas in that of the second series samples and the modifying solution were additionally placed on an ultrasonic bath during the impregnation in order to obtain even coating. Both series of samples were subjected to water contact angle (WCA) measurements using a goniometer. Results of the measurements are presented in Table 1. The results are the arithmetic mean of 10 measurements performed in 5 points of each plate.

Shapes of water drops for selected systems are shown in Fig. 2 as an illustration.

Water contact angles measured for samples prepared by the dip-coating method and by using an ultrasonic bath do not differ significantly and small differences between them are within experimental error, therefore one can conclude that the application of ultrasounds is needless. While comparing WCA values on modified plates one can notice that an increase in the number of fluoroalkyl groups (both OFP and PFD) is accompanied by an increase in WCA and this fact results both from the presence of a greater number of fluoroalkyl groups and from the way of binding between the silsequioxane and glass substrate. In the case of derivatives containing only one trimethoxysilyl group (TMS), binding to the substrate occurs only on one site and this enables the formation of a very flexible surface layer which permits a better orientation of fluoroalkyl groups on the surface. If the surface was modified with derivatives containing 2 or 4 trimethoxysilyl groups, silsesquioxane binding occurs on several sites thus resulting in the surface layer stiffening which does not create favorable conditions for fluoroalkyl group orientation. Moreover, taking into consideration that the distribution of functional groups in a silsesquioxane is statistical, one can expect that fluoroalkyl groups become confined in the interior of the formed polymer layer which

Table 1 WCA of glass surfaces modified with fluorofunctional silsesquioxanes

\begin{tabular}{lll}
\hline silsesquioxane & $\begin{array}{l}\mathrm{WCA}\left[^{\circ}\right] \\
(\text { dip-coated) }\end{array}$ & $\begin{array}{l}\mathrm{WCA}\left[^{\circ}\right] \\
(\text { Sonicated) }\end{array}$ \\
\hline 4PFD-4TMS (1) & $90.5 \pm 0.9(\mathrm{~A})$ & $90.4 \pm 1.1$ \\
6PFD-2TMS (2) & $99.7 \pm 1.3(\mathrm{~B})$ & $96.2 \pm 1.4$ \\
7PFD-1TMS (3) & $124.4 \pm 3.7(\mathrm{C})$ & $123.5 \pm 3.6$ \\
4OFP-4TMS (4) & $98.1 \pm 1.4$ & $88.4 \pm 0.7$ \\
6OFP-2TMS (5) & $98.9 \pm 2.1$ & $97.9 \pm 1.5$ \\
7OFP-1TMS (6) & $115.7 \pm 7.9$ & $109.3 \pm 2.4$ \\
\hline
\end{tabular}

a)

b)



Fig. 2 Water drop shapes with different WCA values on surfaces: a clean glass plate, $\mathbf{b} \mathrm{A}-90.5^{\circ}, \mathbf{c} \mathrm{B}-99.7^{\circ}, \mathbf{d ~ C}-124.4^{\circ}$

causes a decrease of WCA values. Results of our experiments and comparison of water contact angles on coatings prepared on the basis of silsequioxanes containing PFD and OFP groups indicate that the number of fluorine atoms in the alkyl chain and the presence of ether-type oxygen atoms exerts only a slight effect on hydrophobicity of materials obtained. The influence of fluorine atoms is the most clearly seen in the case of surfaces modified with silsesquioxanes containing seven fluoroalkyl groups, albeit the difference in WCA values between derivatives with PFD and OFD groups does not exceed $10^{\circ}$. The modification of a surface with cage structure silsesquioxanes imparts to the surface a certain roughness which results in WCA over $120^{\circ}$. However, taking into consideration nanometric sizes of silsesquioxanes, this diversity of the surface can be too small to obtain even greater WCA values. For this reason in the further part of our study an additional modification of the plates was carried out using silica sol in order to increase surface roughness. Two series of samples were prepared on which silica sol of suitable silica particle size was applied followed by the modification of such prepared plates with one of the fluoroalkyl compounds with different OFP to TMS ratios (see Fig. 3).

Taking into account small differences in WCA on surfaces modified with silsesquioxanes having OFP or PFD groups, as well as considerably greater yields obtained while synthesizing OFP-containing derivatives and their lower price, the latter derivatives (4-6) have been selected for further research. At the first stage, the plates were covered with a silica sol containing silica of different particle size: Aerosil $300(7 \mathrm{~nm})$ and Aerosil $130(16 \mathrm{~nm})$. At the second stage, such prepared plates were modified with functionalized silsesquioxane solution (4-6) analogously to 


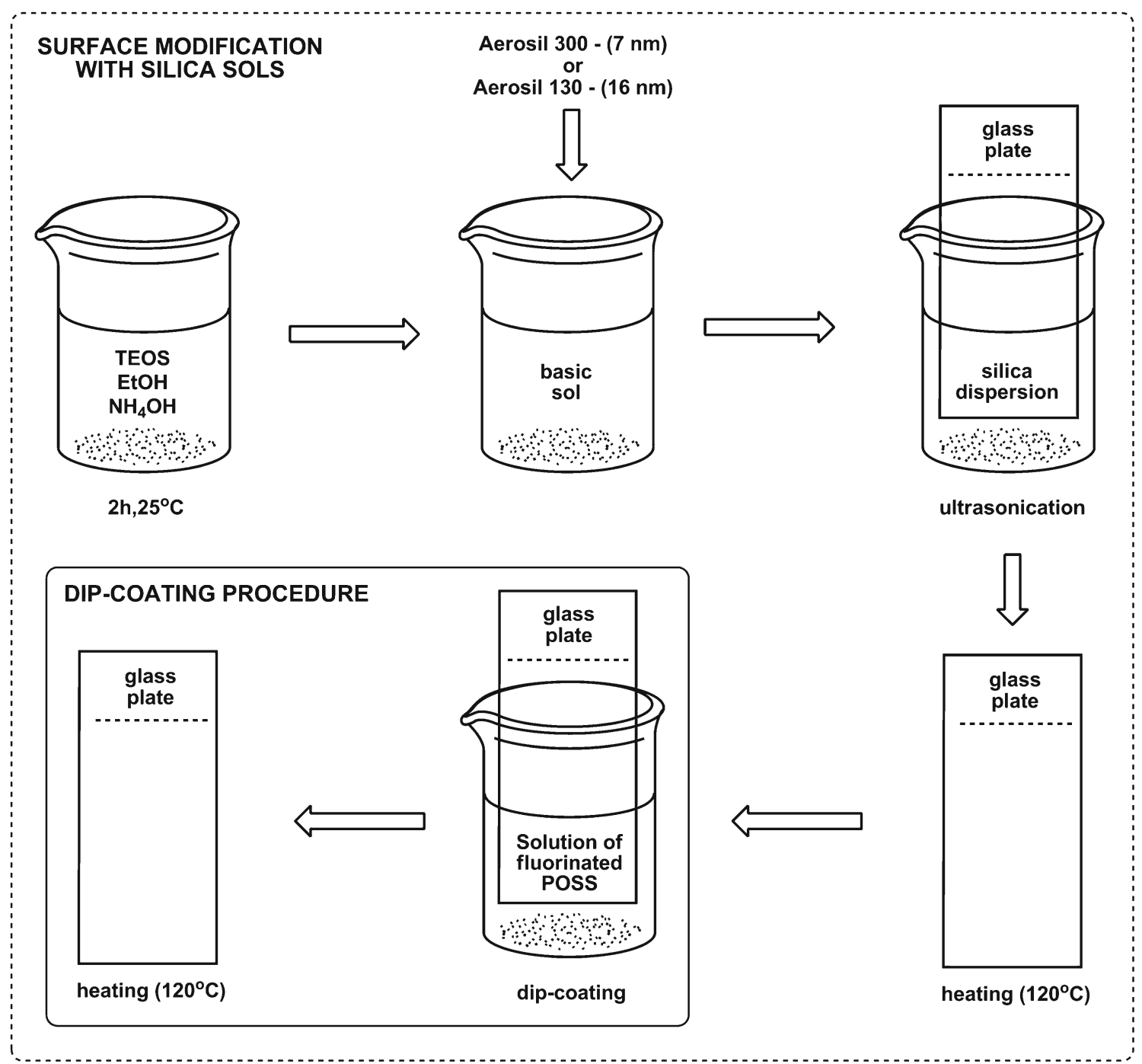

Fig. 3 General procedure for the modification of glass plates

that described above. The application of silica of different particle sizes in order to increase the surface roughness and thereby to create superhydrophobic properties has been reported by different research teams [34-39]. However, in all the cases the role of hydrophobizing agents was played by silanes with long fluoroalkyl chains of high fluorine content, the synthesis of which is neither easy nor cheap. This is why mixed functional groups-containing silsesquioxanes developed by us make an alternative to this group of compounds. Moreover, in the aforementioned papers, in most cases, quite large silica particles (from several dozen nanometers to several micrometers) have been used and this resulted in a greater surface roughness. In our case we have applied nanosilica, particle size of which (7 and $16 \mathrm{~nm}$ ) was only several times greater than the size of the employed silsesquioxanes. WCA values for such modified surfaces are given in Table 2 and examples of drop shapes are shown in Fig. 4.
In all cases, coatings of strongly hydrophobic (and even superhydrophobic) properties were obtained. A precoverage of glass plates with a silica layer resulted in surface diversification which combined with chemical modification with the use of fluorofunctional silsesquioxane resulted in surfaces with strongly hydrophobic properties. A comparison of WCA values shows that silica Aerosil 130 (it has bigger particles: $16 \mathrm{~nm}$ ) produces a greater roughness of

Table 2 Surface modified by silica sols and POSS

\begin{tabular}{lll}
\hline $\begin{array}{l}\text { silsesquioxane } \\
\left.\text { WCA }{ }^{\circ}\right]\end{array}$ & $\begin{array}{l}\mathrm{WCA}\left[{ }^{\circ}\right] \\
(\text { Aerosil 130) }\end{array}$ \\
\hline Silica coated plate & - & - \\
4OFP-4TMS & $129 \pm 3.24$ & $143 \pm 0.66(\mathrm{D})$ \\
6OFP-2TMS & $133 \pm 1.1$ & $149 \pm 0.55(\mathrm{E})$ \\
7OFP-1TMS & $144 \pm 0.72$ & $160 \pm 0.42(\mathrm{~F})$
\end{tabular}




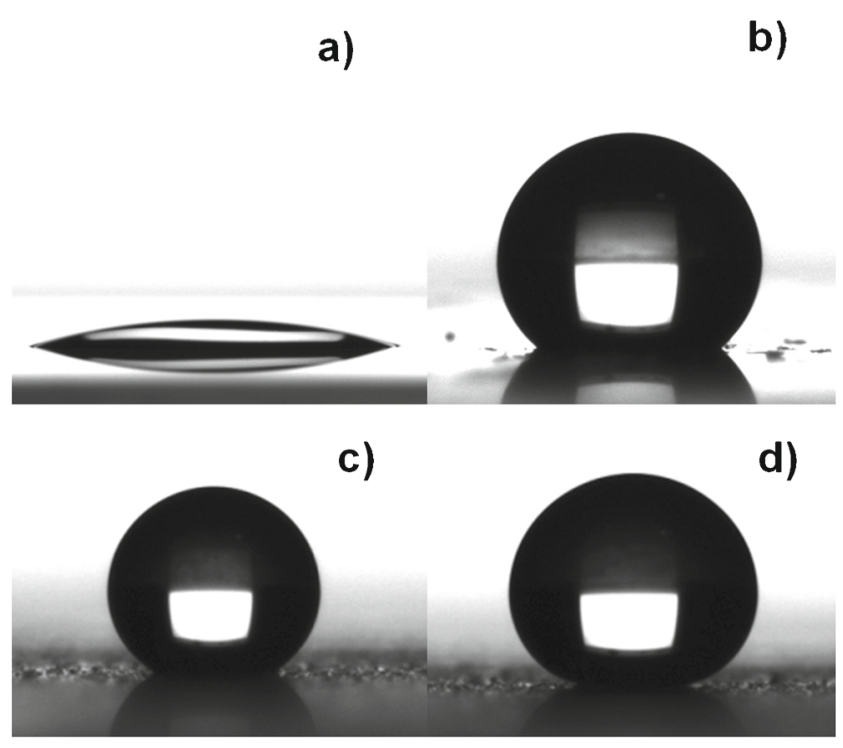

Fig. 4 Water drop shapes with different WCA values on surfaces: a clean glass plate, $\mathbf{b ~ D}-143^{\circ}, \mathbf{c} \mathrm{E}-149^{\circ}, \mathbf{d ~ F}-160^{\circ}$

modified surface than silica Aerosil $300(7 \mathrm{~nm})$, which in combination with the modification with silsesquioxane with the highest number of fluoroalkyl groups (6) makes it possible to obtain superhydrophobic surfaces. The results correlate well with those described for the surface modified with large particle size silica and with fluorofunctional silanes having long fluoroalkyl chains [34-39]. The WCA values for such surfaces are sometimes even greater (although not so considerably) which shows that the structure of silsesquioxanes additionally diversifies the surface. This observation is in agreement with the state of the art; it results from the synergy between chemical and physical modification of surfaces [1, 2]. Moreover, as was the case of the modification of the surface with solutions of pure fluorofunctional silsesquioxanes, the effect of the number of OFP groups on WCA can be noticed. However, WCA is influenced also by the binding between silsesquioxane and surface, i.e. by the number of TMS groups in a silsesquioxane. Changes in WCA values on surfaces modified by silsesquioxanes with four, two and one TMS group (both when the modification was carried out with solutions alone and with the participation of silicas) are presented in Fig. 5.

Note that the change in WCA for surfaces modified with derivatives containing four or two TMS groups is small (from 1 to $5 \%$ ), but in the case of the modification with the derivative containing only one TMS group the difference is greater and equals from 8 to $17 \%$ in spite of the fact that the number of OFP groups is only by one group greater compared to the derivative containing six OFP groups. This confirms the observation that silsesquioxanes attached to

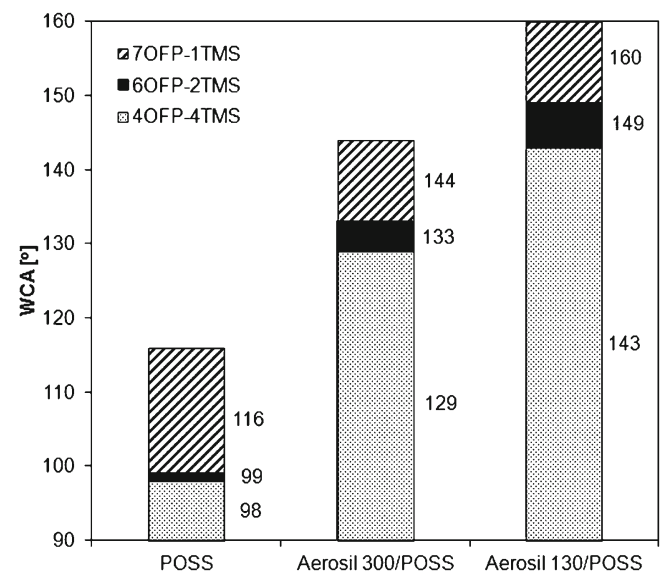

Fig. 5 Comparison of WCA values for all surfaces modified with derivatives of different OFP and TMS content

the substrate via one group have a better capability of orienting fluoroalkyl groups on the surface and increasing hydrophobic properties. The above effect is more clearly seen in the case of surfaces that were additionally modified with silica, where a considerable increasing in WCA occurs for each fluorofunctional silsesquioxane used in the study.

\section{Conclusions}

The application of six prepared derivatives of silsesquioxanes as modifiers of glass surfaces produced hydrophobic surfaces. The most effective appeared to be the derivatives containing seven fluoroalkyl groups and one trialkoxysilyl group which produced coatings with water contact angles ranging from 115 to $124^{\circ}$. The study has shown that derivatives with octafluoropentyloxypropyl groups can be a good alternative to typical fluoroalkyl chains and the presence of ether-type oxygen atoms in their structure affects the effectiveness of hydrophobization of surfaces only to a slight extent. It has been established that hydrophobizing properties of silsesquioxanes are considerably influenced not only by percentage of fluorine atoms, but also by silsesquioxane structure. As expected, the preliminary modification of a glass plate surface with silica resulted in the formation of coatings with superhydrophobic properties. In all studied silica-containing systems high values of water contact angles were obtained. Moreover, irrespectively of particle size of applied silica, a dependence was found between the increase in water contact angle and the number of fluoroalkyl substituents in a molecule. The obtained results have unambiguously shown that fluorofunctional silsesquioxanes having additionally another reactive group (capable of binding to the surface) can be effective hydrophobizing agents and at the same time make an alternative (also from the 
economic viewpoint) to simple fluorofunctional silanes. However, our ultimate aim is to employ this group of derivatives as nanofillers for different polymeric matrices (through a suitable choice of reactive functional groups in silsesquioxanes) and at the same time to impart hydrophobic properties to materials prepared in such a way. Results obtained so far are very promising and will be the subject of our subsequent papers.

Acknowledgments We are grateful to the Ministry of Science and Higher Education (Poland) for financial support (project No N N209 765640).

Open Access This article is distributed under the terms of the Creative Commons Attribution License which permits any use, distribution, and reproduction in any medium, provided the original author(s) and the source are credited.

\section{References}

1. Jiang L, Feng L (2010) Bioinspired Intelligent Nanostructured Interfacial Materials. Chemical Industry Press, New Jersey

2. Liu K, Yao X, Jiang L (2010) Recent development in bioinspired special wettability. Chem Soc Rev 39:3240-3255. doi:10.1039/B917112F

3. Arkles B, Pan Y, Kim YM (2009) The role of Polarity in the Structure of Silanes Employed in Surface Modification. In: Mittal KI (ed) Silanes and other Coupling Agents VSP, Leiden, pp 5165

4. Pagliaro M, Ciriminna R (2005) New fluorinated functional materials. J Mater Chem 15:4981-4991. doi:10.1039/b507583c

5. McKeen LW (2006) Fluorinated Coatings and Finishes Handbook. Wiliam Andrew Publishing, New York

6. Owen MJ (2010) Silicones. In: Clarson SJ, Owen MJ, Smith SD, Van Dyhe ME (eds) Silicones and Silicone Modified Materials ACS Publising

7. Owen, MJ, Dvornic PR (eds) (2010) Silicone Surface Science. Springer Dordrecht

8. Choi W, Tuteja A, Chhatre S, Mabry JM, Cohen RE, McKinley GH (2009) Fabrics with Tunable Oleophobicity. Adv Mater 21:2190-2195. doi:10.1002/adma.200802502

9. Choi W, Tuteja A, Mabry JM, Cohen RE, McKinley GH (2009) A modified CassieBaxter relationship to explain contact angle hysteresis and anisotropy on non-wetting textured surfaces. J Colloid Interf Sci 339:208-216. doi:10.1016/j.jcis.2009.07.027

10. Iacono ST, Bady SM, Mabry JM, Smith DW (2007) Synthesis, characterization, and properties of chain terminated polyhedral oligomeric silsesquioxane-functionalized perfluorocyclobutyl aryl ether copolymers. Polymer 48:4637-4645. doi:10.1016/j.polymer.2007.06.022

11. Tuteya A, Mabry JM (2012) The Design of Non-wetting Surfaces with FluoroPOSS. In: Owen MJ, Dvornic PR (eds) Silicone Surface Science Springer, Dordrecht, pp 179-193

12. Lickiss PD, Rataboul F (2008) Chapter 1 Fully Condensed Polyhedral Oligosilsesquioxanes (POSS): From Synthesis to Application. Adv Organometal Chem 57:1-116. doi:10.1016/S0065-3055(08)00001-4

13. Liu Y, Zheng S, Nie K (2005) Epoxy nanocomposites with octa(propylglycidyl ether) polyhedral oligomeric silsesquioxane. Polymer 46:12016-12025. doi:10.1016/j.polymer.2005.09.056
14. Liu Y, Yang X, Zhang W, Zheng S (2006) Star-shaped poly(caprolactone) with polyhedral oligomeric silsesquioxane core. Polymer 47:6814-6825. doi:10.1016/j.polymer.2006.07.050

15. Itami Y, Marciniec B, Kubicki M (2004) Functionalization of Octavinylsilsesquioxane by Ruthenium-Catalyzed Silylative Coupling versus Cross-Metathesis. Chem Eur J 10:1239-1248. doi:10.1002/chem.200305433

16. Waehner J, Marciniec B, Pawluc P (2007) Functionalization of Vinylspherosilicates by Ruthenium-Catalyzed Silylative Coupling Reactions. Eur J Inorg Chem 8:29752980. doi:10.1002/ejic.200700142

17. Dutkiewicz M, Maciejewski H, Marciniec B (2009) Functionalisation of Polyhedral Oligomeric Silsesquioxanes (POSS) via Nucleophilic Substitution. Synthesis 12:2019-2024. doi:10.1055/s-0029-1216807

18. Hartmann-Thompson C (ed) (2011) Application of Polyhedral Oligomeric Silsesquioxanes. Springer, Dordrecht

19. Iacono ST, Vij A, Grabow W, Smith DW, Mabry JM (2007) Facile synthesis of hydrophobic fluoroalkyl functionalized silsesquioxane nanostructures. Chem Commun 47:4992-4994. doi:10.1039/b712976a

20. Mabry JM, Vij A, Iacono ST, Viers BD (2008) Fluorinated polyhedral oligomeric silsesquioxanes (F-POSS). Angew Chem Int Ed 47:4137-4140. doi:10.1002/anie.200705355

21. Xu J, Li X, Cho CM, Toh CL, Shen L, May KY, Lu X, He C (2009) Polyhedral oligomeric silsesquioxanes tethered with perfluoroalkylthioether corner groups: Facile synthesis and enhancement of hydrophobicity of their polymer blends. J Mater Chem 19:4740-4745. doi:10.1039/b900299e

22. Koh K, Sugiyama S, Morinaga T, Ohno K, Tsujii Y, Fukuda $\mathrm{T}$, Yamahiro M, Iijima T, Oikawa $\mathrm{H}$, Watanabe $\mathrm{K}$, Miyashita $\mathrm{T}$ (2005) Precision synthesis of a fluorinated polyhedral oligomeric silsesquioxane-terminated polymer and surface characterization of its blend film with poly(methyl methacrylate). Macromolecules 38:1264-1270. doi:10.1021/ma0476361

23. Zeng K, Wang L, Zheng S, Qian X (2009) Self-assembly behavior of hepta(3,3,3-trifluoropropyl) polyhedral oligomeric silsesquioxane-capped poly(-caprolactone) in epoxy resin: Nanostructures and surface properties. Polymer 50:685695. doi:10.1016/j.polymer.2008.11.024

24. Dodiuk H, Rios PF, Dotan A, Kenig S (2007) Hydrophobic and self-cleaning coatings. Polym Adv Technol 18:746-750. doi:10.1002/pat.957

25. Jerman I, Orel B, Surca Vuk A, Kozelj M, Kovac J (2010) A structural and corrosion study of triethoxysilyl and perfluorooctyl functionalized polyhedral silsesquioxane nanocomposite films on AA 2024 alloy. Thin Solid Films 518:2710 2721. doi:10.1016/j.tsf.2009.10.02

26. Jerman I, Vuk AS, Koelj M, Orel B, Kova J (2008) A structural and corrosion study of triethoxysilyl functionalized POSS coatings on AA 2024 alloy. Langmuir 24:5029-5037. doi:10.1021/ la7037262

27. Marciniec B, Maciejewski H, Dabek I, Karasiewicz J (2009) Process for the preparation of fluorocarbofunctional alkoxysilanes Pol Pat Appl P-388929

28. Dutkiewicz M, Maciejewski H, Marciniec B, Karasiewicz J (2011) New fluorocarbofunctional spherosilicates: Synthesis and characterization. Organometallics 30:2149-2153. doi:10.1021/om1010337

29. Filho NLD, de Aquino HA, Pires G, Caetano L (2006) Relationship between the dielectric and mechanical properties and the ratio of epoxy resin to hardener of the hybrid thermosetting polymers. J Braz Chem Soc 17:533-541. doi:10.1590/S0103-50532006000300016 
30. Lazzari D, Cassani MC, Solinas G, Pretto M (2013) Fluoroalkyl allyl ethers: Useful building blocks for the synthesis of environmentally safer fluorinated multiblock molecules. J Fluor Chem 156:34-37. doi:10.1016/j.jfluchem.2013.08.003

31. Marciniec B, Krzyzanowski P (1995) Synthesis, characterization and some reactions of $\left[(\text { diene }) \mathrm{Rh}\left(-\mathrm{OSiMe}_{3}\right)\right]_{2}$. J Organomet Chem 493:261-266. doi:10.1016/0022-328X(95)05352-P

32. Marciniec B, Krzyzanowski P, Walczuk-Gusciora E, Duczmal W (1999) Catalytic activity of silyloxy-rhodium(I) complexes in hydrosilylation of alkenes. J Mol Catal 144:263271. doi:10.1016/S1381-1169(99)00109-0

33. Maciejewski H, Karasiewicz J, Marciniec B (2012) Effective synthesis of fluorofunctional (Poly)siloxanes. Polimery 57:449-455. doi:10.14314/polimery.2012.449

34. Prevo BG, Hon EW, Velev OD (2007) Assembly and characterization of Collodi-based antireflective coatings on multicrystalline silicon solar cells. J Mater Chem 17:791-799. doi:10.1039/b612734g
35. Zhang G, Wang D, Gu ZZ, Mohwald H (2005) Fabrication of superhydrophobic surfaces from binary colloidal assembly. Langmuir 21:9143-9148. doi:10.1021/la0511945

36. Tsai HJ, Lee YL (2007) Facile metod to fabricate raspberrylike particulate films for superhydrophobic surfaces. Langmuir 23:12687-12692. doi:10.1021/la702521u

37. Zhang L, Li Y, Sun J, Shen J (2008) Layer-by-layer fabrication of broad-band superhydrophobic antireflection coatings In near-infrared region. J Colloid Inter Sci 319:302-308. doi:10.1016/j.jcis.2007.11.020

38. Xu QF, Wang JN, Sanderson KD (2010) A general approach for superhydrophobic coating with strong adhesion strength. J Mater Chem 20:5961-5966. doi:10.1039/C0JM00001A

39. Boinovich LB, AM Emelyanenko, Muzafarov AM, Myshkovskii AM, Pashinin AS, Tsivadze AYu, Yarova DI (2008) The development of coatings that give superhydrophobic properies to the surface of silicone rubber. Nanotechnologies in Russia 3:587592. doi:10.1134/S1995078008090085 